\title{
RESEARCH
}

Open Access

\section{Physiological cyclic hydrostatic pressure induces osteogenic lineage commitment of human bone marrow stem cells: a systematic study}

Elena Stavenschi ${ }^{1,2}$, Michele A. Corrigan ${ }^{1,2}$, Gillian P. Johnson ${ }^{1,2,3}$, Mathieu Riffault ${ }^{1,2,4}$ and David A. Hoey ${\text {, } 2,3,4^{*}}_{\text {(D) }}$

\begin{abstract}
Background: Physical loading is necessary to maintain bone tissue integrity. Loading-induced fluid shear is recognised as one of the most potent bone micromechanical cues and has been shown to direct stem cell osteogenesis. However, the effect of pressure transients, which drive fluid flow, on human bone marrow stem cell (hBMSC) osteogenesis is undetermined. Therefore, the objective of the study is to employ a systematic analysis of cyclic hydrostatic pressure (CHP) parameters predicted to occur in vivo on early hBMSC osteogenic responses and late-stage osteogenic lineage commitment.
\end{abstract}

Methods: hBMSC were exposed to CHP of $10 \mathrm{kPa}, 100 \mathrm{kPa}$ and $300 \mathrm{kPa}$ magnitudes at frequencies of $0.5 \mathrm{~Hz}, 1 \mathrm{~Hz}$ and $2 \mathrm{~Hz}$ for $1 \mathrm{~h}, 2 \mathrm{~h}$ and $4 \mathrm{~h}$ of stimulation, and the effect on early osteogenic gene expression of COX2, RUNX2 and OPN was determined. Moreover, to decipher whether CHP can induce stem cell lineage commitment, hBMSCs were stimulated for 4 days for $2 \mathrm{~h} /$ day using $10 \mathrm{kPa}, 100 \mathrm{kPa}$ and $300 \mathrm{kPa}$ pressures at $2 \mathrm{~Hz}$ frequency and cultured statically for an additional 1-2 weeks. Pressure-induced osteogenesis was quantified based on ATP release, collagen synthesis and mineral deposition.

Results: CHP elicited a positive, but variable, early osteogenic response in hBMSCs in a magnitude- and frequencydependent manner, that is gene specific. COX2 expression elicited magnitude-dependent effects which were not present for RUNX2 or OPN mRNA expression. However, the most robust pro-osteogenic response was found at the highest magnitude $(300 \mathrm{kPa})$ and frequency regimes $(2 \mathrm{~Hz})$. Interestingly, long-term mechanical stimulation utilising $2 \mathrm{~Hz}$ frequency elicited a magnitude-dependent release of ATP; however, all magnitudes promoted similar levels of collagen synthesis and significant mineral deposition, demonstrating that lineage commitment is magnitude independent. This therefore demonstrates that physiological levels of pressures, as low as $10 \mathrm{kPa}$, within the bone can drive hBMSC osteogenic lineage commitment.

Conclusion: Overall, these findings demonstrate an important role for cyclic hydrostatic pressure in hBMSCs and bone mechanobiology, which should be considered when studying pressure-driven fluid shear effects in hBMSCs mechanobiology. Moreover, these findings may have clinical implication in terms of bioreactor-based bone tissue engineering strategies.

Keywords: Mesenchymal stem cell, Bone, Mechanobiology, Osteogenic differentiation, Bioreactor

\footnotetext{
* Correspondence: dahoey@tcd.ie

${ }^{1}$ Trinity Centre for Bioengineering, Trinity Biomedical Sciences Institute,

Trinity College Dublin, Dublin 2, Ireland

2Department of Mechanical and Manufacturing Engineering, School of

Engineering, Trinity College Dublin, Dublin 2, Ireland

Full list of author information is available at the end of the article
}

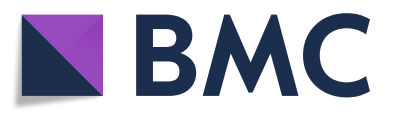

(c) The Author(s). 2018 Open Access This article is distributed under the terms of the Creative Commons Attribution 4.0 International License (http://creativecommons.org/licenses/by/4.0/), which permits unrestricted use, distribution, and reproduction in any medium, provided you give appropriate credit to the original author(s) and the source, provide a link to the Creative Commons license, and indicate if changes were made. The Creative Commons Public Domain Dedication waiver (http://creativecommons.org/publicdomain/zero/1.0/) applies to the data made available in this article, unless otherwise stated. 


\section{Background}

Bone is exposed to constant cyclic loading which is necessary to maintain tissue integrity [1-4]. This effect is mediated in part, by bone marrow stem cells (BMSC), which undergo osteogenic lineage commitment in response to loading to replenish the population of bone-synthesising cells $[5,6]$. Recently, it has been shown that bone marrow stem cells undergo osteogenesis in response to mechanical cues independent of osteocyte signalling, suggesting that the marrow micromechanical environment may directly influence BMSC osteogenesis [6-8]. Given the complex mechanical environment of bone, it is unclear how the translation of macro-scale mechanical cues to the marrow niche directly regulates stem cell differentiation. Fluid flow is recognised as the most potent biophysical stimulus contributing to bone anabolic responses [9-13]. However, the effect of pressure transients, which are necessary to drive the loading-induced fluid flow, on skeletal stem cell osteogenesis is poorly understood. Decoupling the effect of pressure transients from fluid shear on stem cell osteogenesis would identify the driving physical forces in loading induced bone formation, focusing efforts to utilise this information to enhance BMSC osteogenesis and bone repair.

The pressurisation of bone intraosseous fluid plays a critical role in bone mechanics as it provides hydraulic strengthening, as well as forcing the interstitial fluid and marrow, to flow through the lacunar-canalicular system (LCS) and within the medullary cavity, respectively [5, 14]. This, in turn, imparts fluid shear stress stimulation to the resident bone cells, in addition to enhancing mass transport and paracrine signalling [5, 15-18]. Under static conditions, the pressure generated within the marrow medullary cavity, known as intramedullary pressure (IMP), is approximately $4 \mathrm{kPa}$ and related to the systemic blood pressure. However, fluctuations in IMP, which are pulsatile by nature, were found to be dependent on muscular contraction, the rate of loading and anatomic location, with magnitudes quantified up to $50 \mathrm{kPa}[9,19-21]$. In addition, skeletal stem cells resident within Haversian channels and perivascular space may be exposed to pressures up to $300 \mathrm{kPa}$ generated with loading within the LCS $[5,10,22]$. Pressure transients are paramount for the loading-induced bone anabolic response, yet it is not fully understood whether pressure plays a direct role in BMSC osteogenesis independent of the secondary fluid shear. This is of significant importance given that in vitro fluid flow bioreactors rely on pressure gradients to elicit dynamic flow, and these can vary depending on the inertial effects of fluid flow and geometry of the channels [11, 23-25].

One of the earliest studies quantifying the effect of pressure on ossifying long bones and calvaria rudiments demonstrated that cyclic hydrostatic pressure-enhanced mineral deposition, whereas continuous hydrostatic pressure had catabolic consequences [26]. Osteoblasts exposed to cyclic hydrostatic pressure (CHP, 10-40 kPa at $0.3-1 \mathrm{~Hz}$ ) during short- and long-term mechanical stimulation exhibited temporal increases in bone-associated markers, as well as terminal osteoblastogenesis [24, 27-29]. Interestingly, osteoblasts treated with $68 \mathrm{kPa}, 0.5 \mathrm{~Hz} \mathrm{CHP}$ for an hour elicited an increase in the expression of the bone-associated marker, cyclo-oxygenase 2 (Cox2), whereas treatment of human bone marrow stem cells with a similar magnitude, but at $2 \mathrm{~Hz}$ frequency, did not mimic this response [24, 30]. In contrast, short-term administration of $10-36 \mathrm{kPa}$ of hydrostatic or cyclic pressure $(0.25 \mathrm{~Hz})$ was sufficient to elicit an early osteogenic response in the expression of runt-related transcription factor 2 (Runx2), Osterix (Osx), distal-less homeobox 5 ( $D l x 5)$, Msh homeobox 2 (Msx2), bone morphogenetic protein 2 (BMP2) and alkaline phosphatase (ALP) in bone marrow-derived stem cells [31, 32]. Furthermore, 21-day treatment of $10 \mathrm{kPa}$ hydrostatic pressure (HP) per day in osteogenic biochemical induction medium was sufficient to induce osteogenic lineage commitment of hBMSCs, whereas $90 \mathrm{kPa}$ HP per day for 2 weeks after biochemical induction did not alter mineral deposition [31, 33]. Therefore, given the variable response to pressure in bone cells and limited analysis in human osteoprogenitors, a systematic study that investigates the effect of physiologically relevant pressure on osteogenic responses in human skeletal stem cells is required.

Therefore, the objective of this study is to conduct a systematic analysis of cyclic hydrostatic pressure magnitude, frequency and duration on early osteogenic responses and to determine whether these mechanical stimuli are sufficient to drive osteogenic lineage commitment of bone marrow-derived skeletal stem cells in the long term. Understanding how bone micromechanical cues modulate osteogenic hBMSCs potential, independent of fluid flow, may open new avenues for orthopaedic regenerative medicine strategies in addition to providing novel platforms to characterise loading induced skeletal stem cell osteogenesis.

\section{Methods}

\section{Cell culture}

All materials were purchased from Sigma-Aldrich unless otherwise stated. Human bone marrow-derived skeletal stem cells (hBMSCs) were isolated from bone marrow aspirates (Lonza) and characterised by trilineage differentiation (Additional file 1: Figure S1). hBMSCs were cultured on fibronectin $(10 \mu \mathrm{g} / \mathrm{ml}$, Corning) coated glass slides in low glucose DMEM supplemented with $10 \%$ foetal bovine serum (FBS, Biosera) and 1\% penicillin-streptomycin (P/S) 
unless otherwise stated. For short-term mechanical stimulation, cells were cultured for $24 \mathrm{~h}$ under standard conditions followed by $48 \mathrm{~h}$ of serum starvation $(0.5 \% \mathrm{FBS})$ supplemented with $10 \mathrm{nM}$ dexamethasone, $0.025 \mathrm{mM} \mathrm{L}$-ascorbic acid and $10 \mathrm{mM} \beta$-glycerol phosphate. These concentrations represent minimal levels for the support of osteogenesis, thereby allowing greater scope to investigate the effect of a biophysical versus a biochemical stimulus [11]. Regarding long-term cyclic hydrostatic pressure stimulation, the cells were cultured in similar conditions, except supplemented with $2 \% \mathrm{FBS}$ and $2 \% \mathrm{P} / \mathrm{S}$.

\section{Pressure bioreactor design}

The design of the pressure bioreactor is based on the principle of fluid incompressibility whereby delivery of a finite bolus of fluid at various pressure rates in a closed system elicits a time-dependent pressure differential. The bioreactor system configuration is composed of a syringe pump (NE1660, New Era Pump Systems) which holds the syringe connected to the custom pressure bioreactor via tubing and a valve, a port on the pressure chamber for real-time pressure oscillations measurement (optional) and a pressure sensor (0-10 kPa: HSCMANV015PGAA5, 0100 kPa: SSCDANV150PGAA5, Honeywell) interfaced with LABVIEW Virtual Instrument (Laboratory Virtual Instrument Engineering Workbench, National Instruments) to monitor and record pressure oscillations over time (Fig. 1a). The pressure bioreactor system was empirically validated for pressure magnitudes of $10 \mathrm{kPa}, 100 \mathrm{kPa}$ and $300 \mathrm{kPa}$ at frequencies of $0.5 \mathrm{~Hz}, 1 \mathrm{~Hz}$ and $2 \mathrm{~Hz}$. These pressure magnitudes have been predicted to occur within the bone marrow cavity and lacunar-canalicular system of bone $[5,10]$ whilst the employed frequencies are representative of human locomotion (Fig. 1b, c) [34, 35]. Given that fluid pressure is delivered to create a transient cyclic pressure differential, the shear stress was assumed to be negligible as volumes less than $2 \mathrm{ml}$ were infused in a system of $50 \mathrm{ml}$ of the medium. This was validated using blue dye to visualise the fluid streams during infusion/withdrawal phase where the dye reached only $1 / 3$ of tubing and was not present within the chamber itself (data not presented). Hence, this allows for delineating the effect of pressure independent of fluid shear on the osteogenic commitment of hBMSCs.

\section{Cyclic hydrostatic pressure (CHP) mechanical stimulation}

To systematically delineate the effect of cyclic hydrostatic pressure magnitude, frequency and duration on the early osteogenic response of hBMSCs, a series of $\mathrm{CHP}$ regimes were employed (Table 1). The range of pressure magnitudes selected represent the physiological pressures elicited within marrow just by muscle contraction independent of whole bone loading $(\sim 10 \mathrm{kPa})$ and pressure elicited within the lacunar canalicular system due to whole bone loading $(300 \mathrm{kPa})[5,21]$. The frequencies of $0.5-2 \mathrm{~Hz}$ range are representative of human locomotion whereas the duration of mechanical stimulation is based on previous mechanobiology studies [11, $35,36]$. The CHP parameters were grouped such as to examine the independent effect of peak shear stress, frequency and duration of early osteogenesis. In addition, frequency and CHP duration were coupled such that comparisons of CHP regimes with a constant number of loading cycles can be made, i.e. $0.5 \mathrm{~Hz}, 4 \mathrm{~h}$ against $1 \mathrm{~Hz}$,
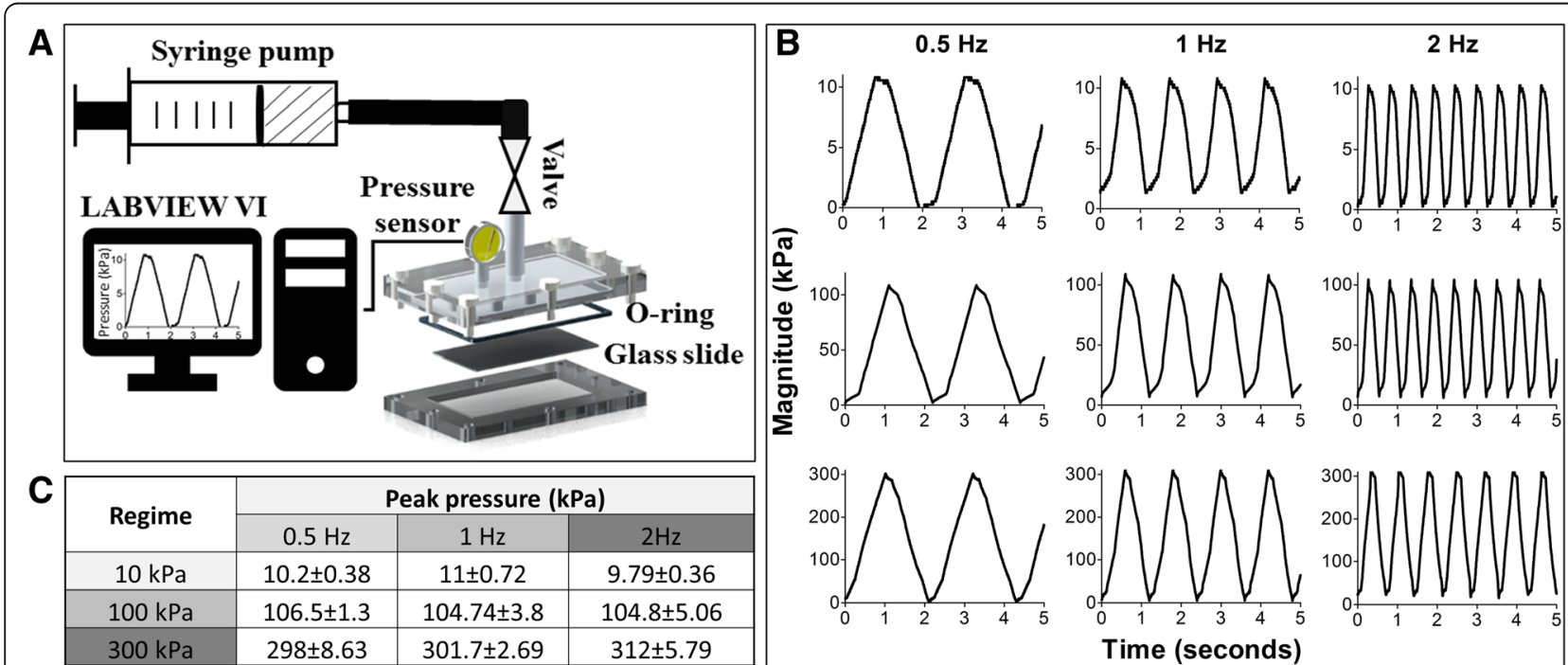

Fig. 1 Pressure bioreactor design configuration (a) and validation of cyclic hydrostatic pressure regimes of $10 \mathrm{kPa}, 100 \mathrm{kPa}$ and $300 \mathrm{kPa}$ at frequencies of $0.5 \mathrm{~Hz}, 1 \mathrm{~Hz}, 2 \mathrm{~Hz}$. Representative traingular waveforms for each regime (b) and average peak pressures measured at room temperature represented as mean $\pm \mathrm{SD}, n=3$ (c) 
Table 1 Experimental conditions for short-term fluid pressure stimulation

\begin{tabular}{lllll}
\hline $\begin{array}{l}\text { Shear } \\
\text { stress }\end{array}$ & Frequency & & & $\begin{array}{l}\text { Infused } \\
\text { volume/ } \\
\text { cycle } \\
\text { (ml) }\end{array}$ \\
\cline { 2 - 5 } & $0.5 \mathrm{~Hz}(\mathrm{~h})$ & $1 \mathrm{~Hz}(\mathrm{~h})$ & $2 \mathrm{~Hz}(\mathrm{~h})$ & $\leq 0.03$ \\
\hline $10 \mathrm{kPa}$ & 2,4 & 2 & 1,2 & $\leq 0.375$ \\
$100 \mathrm{kPa}$ & 2,4 & 2 & 1,2 & $\leq 1.5$ \\
$300 \mathrm{kPa}$ & 2,4 & 2 & 1,2 & \\
\hline
\end{tabular}

$2 \mathrm{~h}$ and $2 \mathrm{~Hz}, 1 \mathrm{~h}$. This approach is based on a previous systematic investigation of oscillatory fluid flow on mesenchymal stem cells [11]. The static condition for both short- and long-term stimulation consisted of culture slides assembled within chambers and were left open to atmospheric pressure (control). To determine whether cyclic hydrostatic pressure can induce osteogenic lineage commitment, hBMSCs were subjected to three separate CHP regimes over a long-term duration, based on our results from the short-term systematic analysis. The three chosen CHP regimes of $10 \mathrm{kPa}, 2 \mathrm{~Hz}, 100 \mathrm{kPa}, 2 \mathrm{~Hz}$ and $300 \mathrm{kPa}, 2 \mathrm{~Hz}$ were applied intermittently on days 3 , 5,7 and 9 for $2 \mathrm{~h} /$ day and subsequently cultured statically for an additional 7 and 14 days (experimental plan illustrated in Additional file 1: Figure S2).

\section{Quantitative real-time PCR}

Cells were lysed using TRI Reagent ${ }^{\circ}$ (Sigma Aldrich), and mRNA was isolated according to the manufacturer's protocol. One microgram of RNA was reverse transcribed into cDNA using High Capacity cDNA kit (Life Technologies). Quantitative polymerase chain reaction (qPCR) was performed using SYBR Select Mastermix (ThermoFisher 4472903). The expression of $18 \mathrm{~S}$ ribosomal RNA (18S), glyceraldehyde 3-phosphate dehydrogenase $(G A P D H)$, cyclooxygenase 2 (COX2), runt-related transcription factor 2 (RUNX2) and OSTEOPONTIN $(O P N)$ were quantified using primers detailed in Table 2 (Sigma Aldrich). The amplification was performed with an ABI7500 Fast Real-Time PCR machine. Each sample was normalised to reference genes $18 S$ and GAPDH and to static control using relative quantification method.

\section{Adenosine triphosphate assay}

After mechanical stimulation for each time point (1, 2 and $4 \mathrm{~h}$ for days 3, 5, 7 and 9), the cells were incubated in $1 \mathrm{ml}$ of medium after which the medium was collected and snap frozen in liquid nitrogen following storage at $-80^{\circ} \mathrm{C}$. Adenosine triphosphate (ATP) metabolites within the media were measured using Molecular Probes ${ }^{\circ}$ ATP Determination Kit (A22066, Invitrogen) according to the manufacturer's protocol. Luminescence was measured using Luminoskan ${ }^{\mathrm{Tm}}$ Ascent Microplate Luminometer (MTX LAB SYSTEMS).

\section{Osteogenic assays}

Cells were fixed in formalin for $10 \mathrm{~min}$. For collagen staining, cells were incubated in $0.1 \%$ Picro-Sirius Red solution for $1 \mathrm{~h}$ at room temperature. After washing twice in $0.5 \%$ acetic acid and water, samples were mounted with DPX mounting medium. Calcium staining was performed using 2\% Alizarin Red solution. The bound dye for both calcium and collagen was observed under light microscopy. The bound Alizarin Red was used to quantify the calcium content by extraction using 10\% $v / v$ acetic acid and measuring the absorbance at $405 \mathrm{~nm}$.

\section{Statistical analysis}

All data is presented as mean $\pm \mathrm{SEM}$. For qRT-PCR analysis, each condition was compared to matched static control using a two-tailed student's $t$-test with Welch's correction. CHP to static control (C) is denoted as " $p<$ $0.05,{ }^{* *} p<0.01$ and ${ }^{* * *} p<0.005$. One-way ANOVA with the Tukey post hoc test was used to compare the effect of magnitude, frequency and duration, and significant differences are indicated as ${ }^{\#} p<0.05,{ }^{\# \#} p<0.01$ and ${ }^{\# \# \#}$ $p<0.005$ except for the 2-h group, where a two-way ANOVA analysis was employed with the Bonferroni post

Table 2 Primers and experimental conditions used for QPCR analysis

\begin{tabular}{|c|c|c|c|c|}
\hline Gene & $\operatorname{Tm}\left({ }^{\circ} \mathrm{C}\right)$ & Primer concentration (nM) & Sequence & PCR product size (bp) \\
\hline \multirow[t]{2}{*}{185} & 60 & 300 & 5'- ATCGGGGATTGCAATTATTC -3' & 130 \\
\hline & & & $3^{\prime}-$ CTCACTAAACCATCCAATCG -5' & \\
\hline \multirow[t]{2}{*}{ GAPDH } & 60 & 300 & 5'- ACAGTTGCCATGTAGACC -3' & 95 \\
\hline & & & 3'- TाTाTGGTTGAGCACAGG -5' & \\
\hline \multirow[t]{2}{*}{$\operatorname{cox} 2$} & 60 & 400 & 5'- GGAGAAAAGGAAATGTCTGC -3' & 186 \\
\hline & & & 3'- GTAGGCAGGAGAACATATAAC -5' & \\
\hline \multirow[t]{2}{*}{ RUNX2 } & 60 & 400 & 5'- GCAGTATTTACAACAGAGGG -3' & 112 \\
\hline & & & 3'- TCCCAAAAGAAGTITTGCTG -5' & \\
\hline \multirow[t]{2}{*}{ OPN } & 60 & 400 & 5'- GACCAAGGAAAACTCACTAC - $3^{\prime}$ & 84 \\
\hline & & & 3'- CTGTTTAACTGGTATGGCAC -5' & \\
\hline
\end{tabular}


hoc test. For calcium quantification, a one-way ANOVA with Dunnett's post-test was performed.

\section{Results \\ Cyclic hydrostatic pressure bioreactor design and validation}

The design of the pressure bioreactor system was modelled on our previously developed fluid shear bioreactor due to its ease of use and the compatibility of glass slides for cell culture and syringe pumps for mechanical stimulation (Fig. 1a). The custom pressure bioreactor was designed to allow for pressure stimulation of cells seeded on 2D substrates (i.e. glass or polydimethylsiloxane), in addition to cells seeded on three-dimensional scaffolds. By harnessing the power of fluid incompressibility, cyclic pressure transients can be achieved by applying a cyclic oscillatory fluid flow of finite volumes of fluid, in a closed system filled with culture medium. Using an external port which allows for real-time measurement of pressures, the pressure bioreactor was validated to generate pressure transients of $10 \mathrm{kPa}, 100 \mathrm{kPa}$ and $300 \mathrm{kPa}$ at frequencies of $0.5 \mathrm{~Hz}, 1 \mathrm{~Hz}$ and $2 \mathrm{~Hz}$ with a triangular waveform (Fig. 1b). The average peak pressures achieved using this system are within $15 \%$ of nominal pressures.

\section{Effect of CHP magnitude on early osteogenic gene expression in hBMSCs}

Stimulation of hBMSCs with cyclic hydrostatic pressure displays a variable osteogenic response based on mRNA expression of the osteogenic markers COX2, RUNX2 and OPN compared to static conditions. COX2 mRNA expression is upregulated in response to $\mathrm{CHP}$ in a magnitude dependent manner (Fig. 2a). This is particularly evident in the $0.5 \mathrm{~Hz}, 2 \mathrm{~h}, 0.5 \mathrm{~Hz}$, $4 \mathrm{~h}$ and $2 \mathrm{~Hz}, 2 \mathrm{~h}$ groups, significant only for the two latter groups $(p<0.001)$. In addition, the highest expression within these groups is achieved at $300 \mathrm{kPa}$ magnitude and is significantly different to $10 \mathrm{kPa}$ and $100 \mathrm{kPa}(p<0.05)$. Interestingly, for the $2 \mathrm{~Hz}, 1 \mathrm{~h}$ and $1 \mathrm{~Hz}, 2 \mathrm{~h}$ groups, a consistent approximately twofold change is maintained, displaying little effect of magnitude. This may be attributed to a synergistic time effect as significant magnitude effects are present at a longer duration of stimulation. Overall, CHP did not cause any changes in RUNX2 expression, except an inhibitory magnitude effect was present at the $0.5 \mathrm{~Hz}, 4 \mathrm{~h}$ time point $(p<0.05)$ and a significantly decreased expression at $10 \mathrm{kPa}$ and $300 \mathrm{kPa}$ at $1 \mathrm{hz}$, $2 \mathrm{~h}(p<0.05)$ (Fig. 2b). OPN mRNA expression displayed an inhibitory effect at lower magnitudes of CHP, with a positive magnitude effect for the $2 \mathrm{~Hz}$, $2 \mathrm{~h}$ and $0.5 \mathrm{~Hz}, 4 \mathrm{~h}$ groups $(p<0.05)$ (Fig. $2 \mathrm{c}$ ).

\section{Effect of CHP frequency on early osteogenic gene expression in hBMSCs}

To identify whether CHP frequency affects early osteogenic mRNA expression, the $2 \mathrm{~h}$ pressure group was analysed for $0.5 \mathrm{~Hz}, 1 \mathrm{~Hz}$ and $2 \mathrm{~Hz}$ frequencies. Pressure-induced COX2 mRNA expression displays a similar level of upregulation at all magnitudes irrespective of frequencies, except at $300 \mathrm{kPa}$, where a frequency effect is present $(p<0.001)$ (Fig. 3a). Interestingly, for RUNX2 and OPN mRNA expression, a frequency effect is present only at $10 \mathrm{kPa}$ magnitude $(p<0.05)$. Specifically, OPN mRNA expression at $10 \mathrm{kPa}$ was least inhibitory at $1 \mathrm{~Hz}$ compared to $0.5 \mathrm{~Hz}$ and $2 \mathrm{~Hz}(p<0.001)$. This effect is also present at $100 \mathrm{kPa}$, although not significant for frequency effects. Hence, the frequency of pressure stimulation plays a role at higher magnitudes for COX2 expression and at lower magnitudes for RUNX2 and OPN mRNA expression.

\section{Effect of CHP duration on early osteogenic gene expression in hBMSCs}

To identify the effect of duration on early osteogenic expression, $1 \mathrm{~h}$ and $2 \mathrm{~h}$, as well as $2 \mathrm{~h}$ and $4 \mathrm{~h}$ of stimulation, were compared while other parameters were held constant. Overall, COX2 mRNA expression displayed similar levels of upregulation over time, except at $300 \mathrm{kPa}, 2 \mathrm{~Hz}$ frequency where a higher response was observed when stimulated for longer durations $(p<$ 0.001) (Fig. 4a). In contrast, RUNX2 mRNA expression displayed no changes over time for the compared groups, except at $300 \mathrm{kPa}$ where a significant decrease at $4 \mathrm{~h}$ versus $2 \mathrm{~h}$ was noted $(p<0.05)$. When comparing the $1 \mathrm{~h}, 2 \mathrm{~Hz}$ with $2 \mathrm{~h}, 1 \mathrm{~Hz}$ and $4 \mathrm{~h}, 0.5 \mathrm{~Hz}$ groups, all of which experience the same cyclic hydrostatic pressure magnitude and number of oscillating cycles (7200), there is a clear abrogated response with the longer duration for $10 \mathrm{kPa}$ and $300 \mathrm{kPa}$ suggesting that RUNX2 expression may have a time dependency effect (Fig. 4b). No changes over time were observed for OPN mRNA expression except an inhibitory effect at $10 \mathrm{kPa}$ at $2 \mathrm{~h}$ versus $1 \mathrm{~h}(p<0.05)$ and a significant upregulation at $4 \mathrm{~h}$ versus $2 \mathrm{~h}$ at $300 \mathrm{kPa}(p<0.05)$ (Fig. 4c). Therefore, duration of mechanical stimulation plays a role in the level of upregulation of osteogenic markers although this effect is gene and magnitude dependent.

\section{Effect of long-term intermittent CHP on the osteogenic lineage commitment of hBMSCs}

Based on the systematic analysis performed above, where the most robust osteogenic gene expression was observed at $2 \mathrm{~Hz}$ frequency for all pressure magnitudes, these three pressure regimes were brought forward to verify whether $\mathrm{CHP}$ can induce the osteogenic lineage commitment of hBMSCs. Therefore, the pressure regimes of $10 \mathrm{kPa}$, 


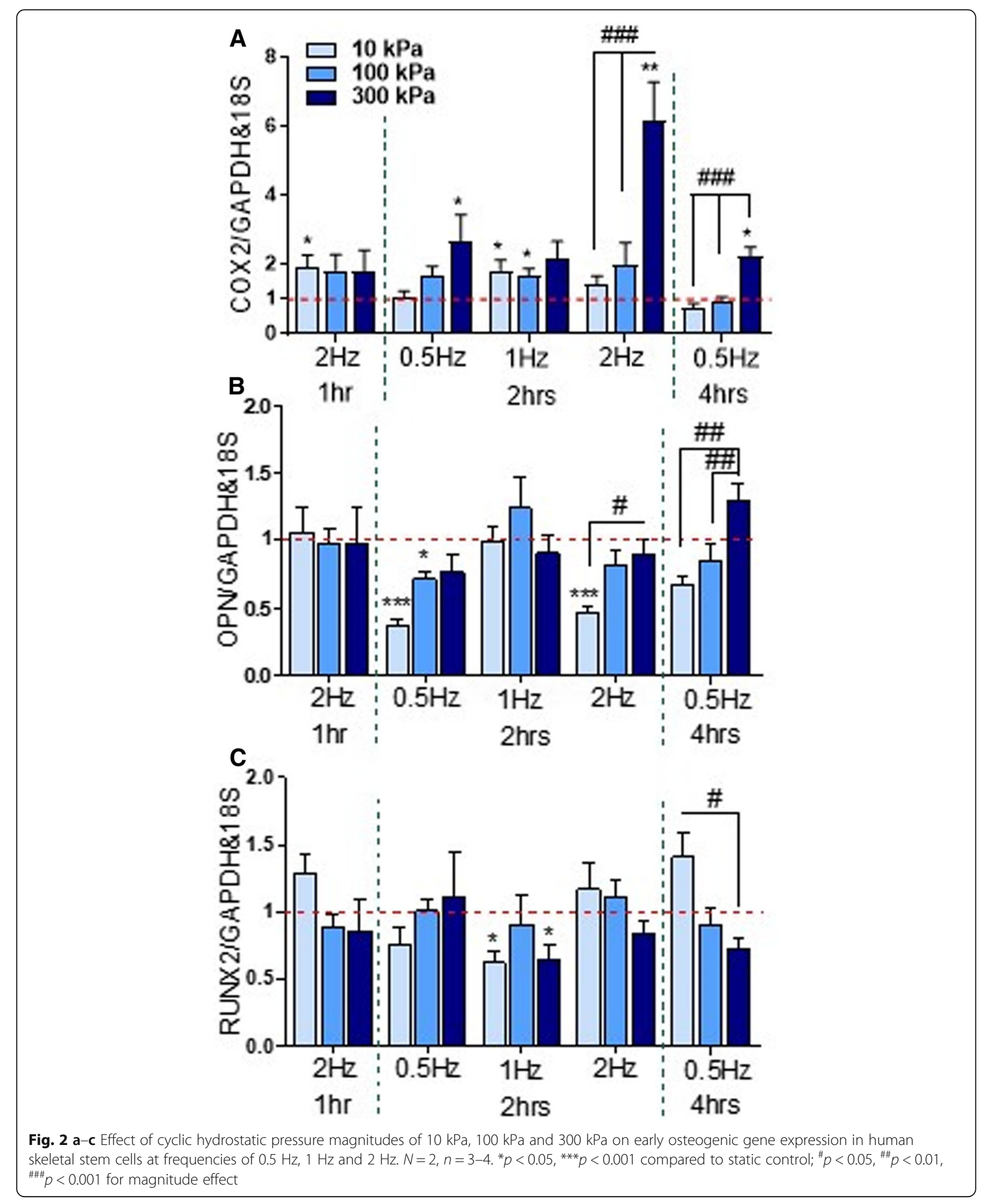




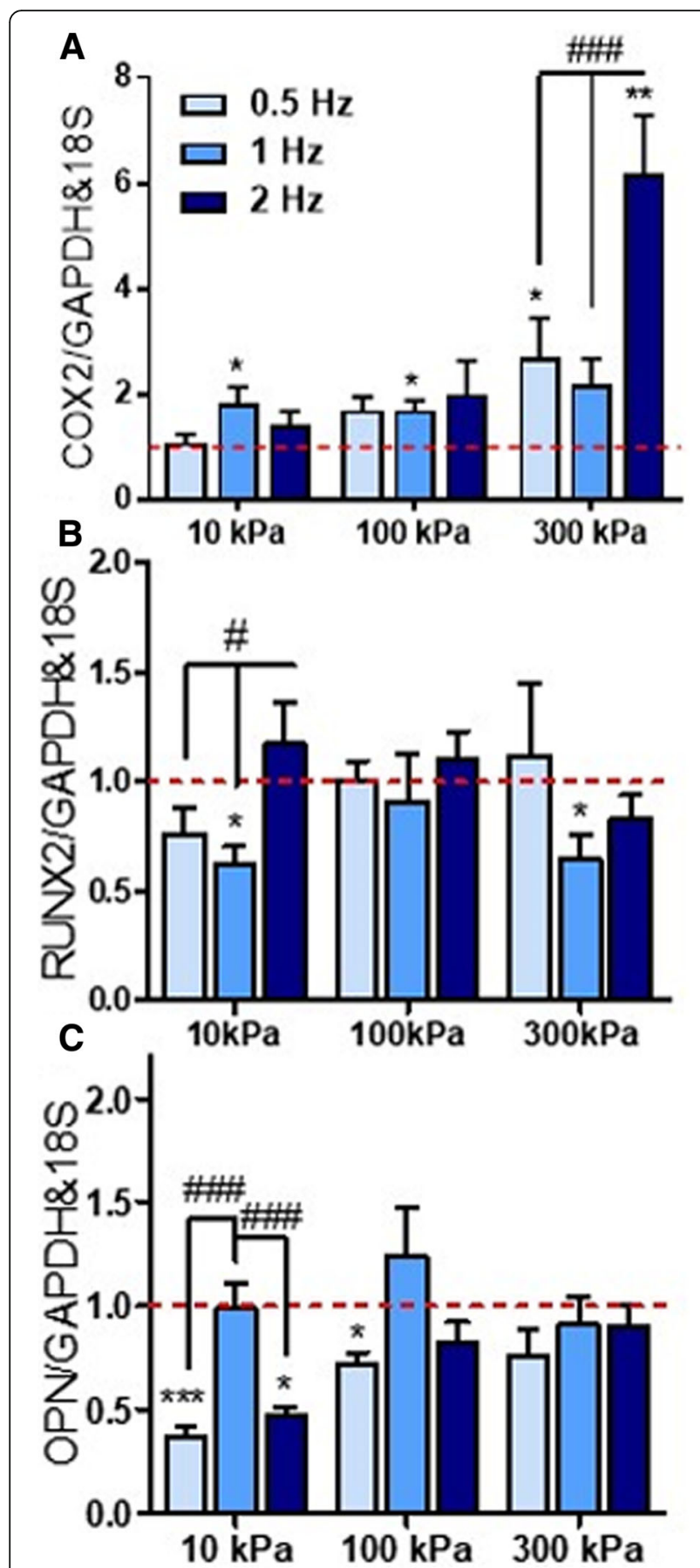

Fig. 3 a-c Effect of CHP frequency $(0.5 \mathrm{~Hz}, 1 \mathrm{~Hz}$ and $2 \mathrm{~Hz})$ on early osteogenic gene expression for $10 \mathrm{kPa}, 100 \mathrm{kPa}$ and $300 \mathrm{kPa}$ pressure magnitudes ( $2 \mathrm{~h}$ duration). $N=2, n=3-4 .{ }^{*} p<0.05,{ }^{* * *} p<$ 0.001 compared to static control; ${ }^{\#} p<0.05,{ }^{\# \#} p<0.01,{ }^{\# \# \#} p<0.001$ for magnitude effect

$100 \mathrm{kPa}$ and $300 \mathrm{kPa}$ at $2 \mathrm{~Hz}$ frequency were applied once per day for a total of 4 days followed by 1 and 2 weeks of static culture. Furthermore, to determine whether the hBMSCs were responsive throughout the long-term CHP stimulation, ATP release after $1 \mathrm{~h}$ of stimulation was

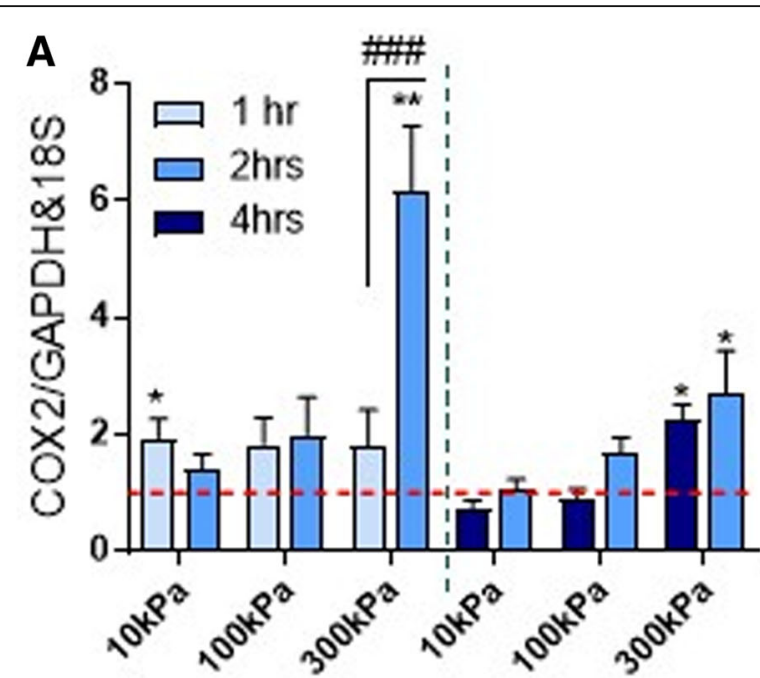

B

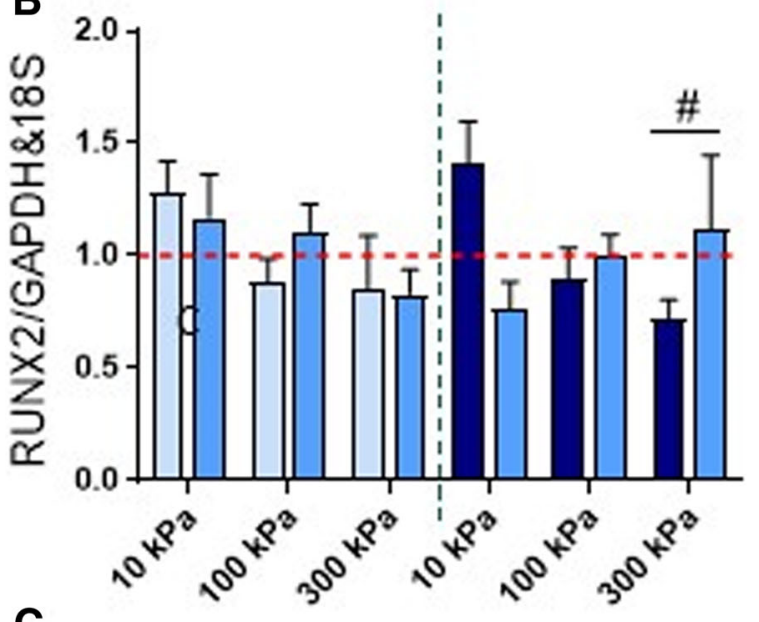

C

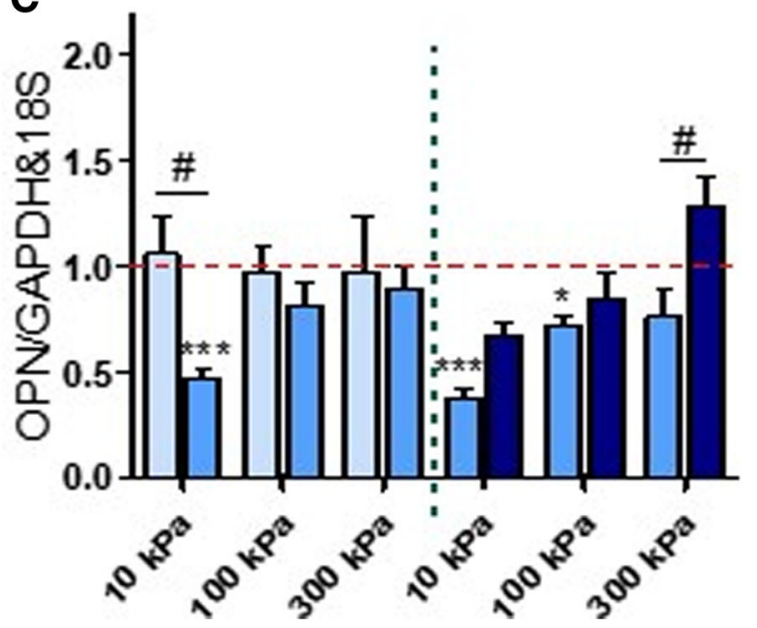

Fig. 4 a-c Effect of duration of CHP stimulation on early osteogenic gene expression at frequencies of $0.5 \mathrm{~Hz}(2$ and $4 \mathrm{~h}$ ) and $2 \mathrm{~Hz}$ ( 1 and 2 h). $N=2, n=3-4 .{ }^{*} p<0.05,{ }^{* * *} p<0.001$ compared to static control; ${ }^{\#} p<0.05,{ }^{\# \#} p<0.01,{ }^{\# \# \#} p<0.001$ for magnitude effect 
determined on each day of pressure stimulation (Fig. 5). ATP release within the media of the stimulated hBMSCs when compared to static controls, displayed a pressure magnitude effect $(p<0.05)$ for all days except day 7. Ten-kilopascal pressure did not induce ATP release at any time point. There was a trend towards significance at $100 \mathrm{kPa}$ at day 3 and day $5(p<0.07$ at day $3, p<0.14$ at day 5 ), while there was a consistent increase in ATP release following $300 \mathrm{kPa}$ pressure $(p<0.05)$ at days 3,5 and 9. The continuous ATP release over-time confirms that hBMSCs maintained their mechanoresponsiveness over extended periods of pressure stimulation and confirms the magnitude effect of pressure stimulation demonstrated above.

After relatively short-term CHP treatment (4 days), followed by a 2-week static culture, collagen synthesis is observed in all groups. However, the pressure stimulated groups displayed regions of increased collagen deposition when compared to static conditions (Fig. 6). No distinct qualitative differences in collagen synthesis are noted between the CHP groups. Regarding mineralisation1-week post $\mathrm{CHP}$ stimulation, there is a slight but significant increase in mineral deposition for the high magnitude $300 \mathrm{kPa}, 2 \mathrm{~Hz}$ group $(p<0.01)$ (Fig. 7a). However, at 2 weeks post pressure stimulation, quantification of Alizarin Red S staining shows a significant increase in calcium deposition with CHP in all groups $(p<0.05)$, with no difference between each magnitude of pressure. The presence of mineralised nodules is detected for all the CHP regimes as illustrated in Fig. 7c. Therefore, physiologically relevant cyclic hydrostatic pressures predicted to occur within the bone and marrow cavity is sufficient to directly drive osteogenic lineage commitment of human stem cells independent of pressure magnitude in the long term, despite demonstrating early magnitude dependent effects.

\section{Discussion}

We have previously demonstrated that physiological levels of fluid flow that are predicted to occur within bone marrow niche, drive stem cell osteogenic lineage commitment in a shear stress and magnitude dependent manner [11]. However, the effect of pressurisation of the intraosseous fluid, which drives this fluid flow, and its effects independent of fluid shear on stem cell osteogenesis is poorly understood. For the first time, we report a systematic in vitro analysis on the effect of physiological CHP magnitude, frequency and duration on human bone marrow stem cell osteogenic responses. Through the utilisation of custom-built pressure bioreactors, we demonstrated that $\mathrm{CHP}$ elicits a variable, yet, positive osteogenic response in hBMSCs in a magnitude, frequency, and duration-dependent manner, that is gene specific. Furthermore, long-term mechanical stimulation utilising $10-300 \mathrm{kPa}$ pressure magnitudes at $2 \mathrm{~Hz}$ frequency promoted collagen synthesis and significant mineral deposition compared to static control, proving that physiological levels of pressure elicited within the marrow and bone with loading is sufficient to directly drive osteogenic lineage commitment. Moreover, mineral deposition due to CHP stimulation was found to be independent of pressure magnitude, despite early osteogenic magnitude dependent effects. These findings highlight that bone marrow physiological CHP can directly drive stem cell osteogenesis, independent of fluid flow, which

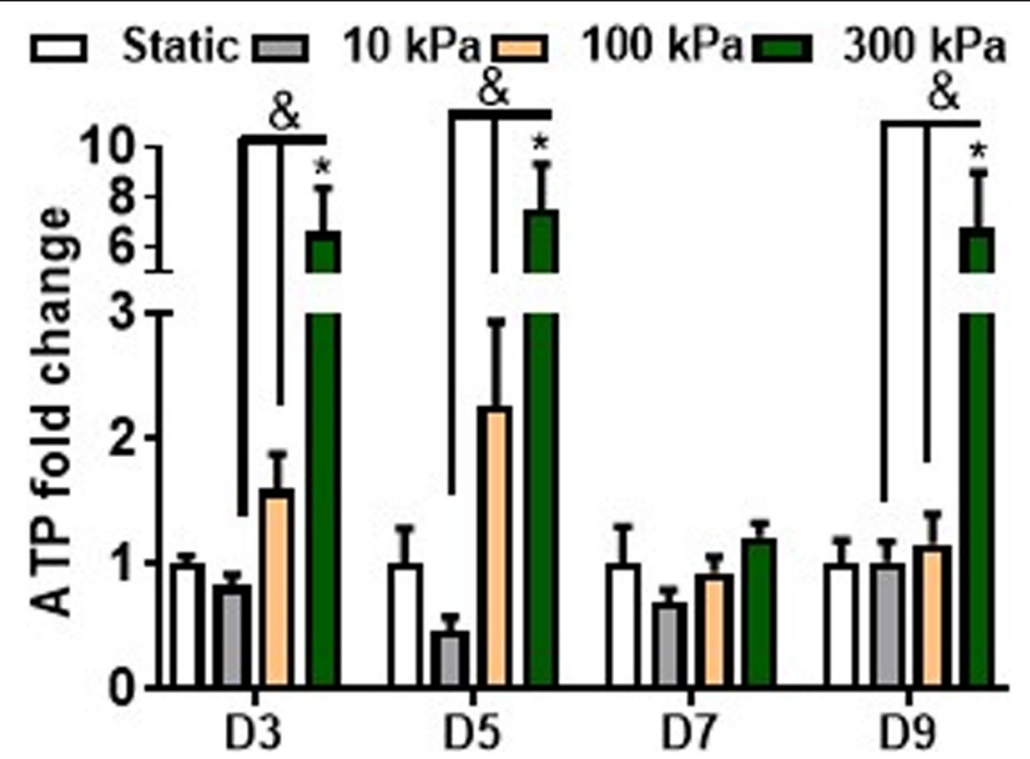

Fig. 5 ATP release over time during long-term intermittent pressure stimulation. The effects of intermittent pressure on ATP release at days 3, 5, 7 and 9 after $1 \mathrm{~h}$ of mechanical stimulation. $n=4-6 .{ }^{*} p<0.05$ compared to either $S ;{ }^{\circledR} p<0.05$ for effect of pressure magnitude effect 


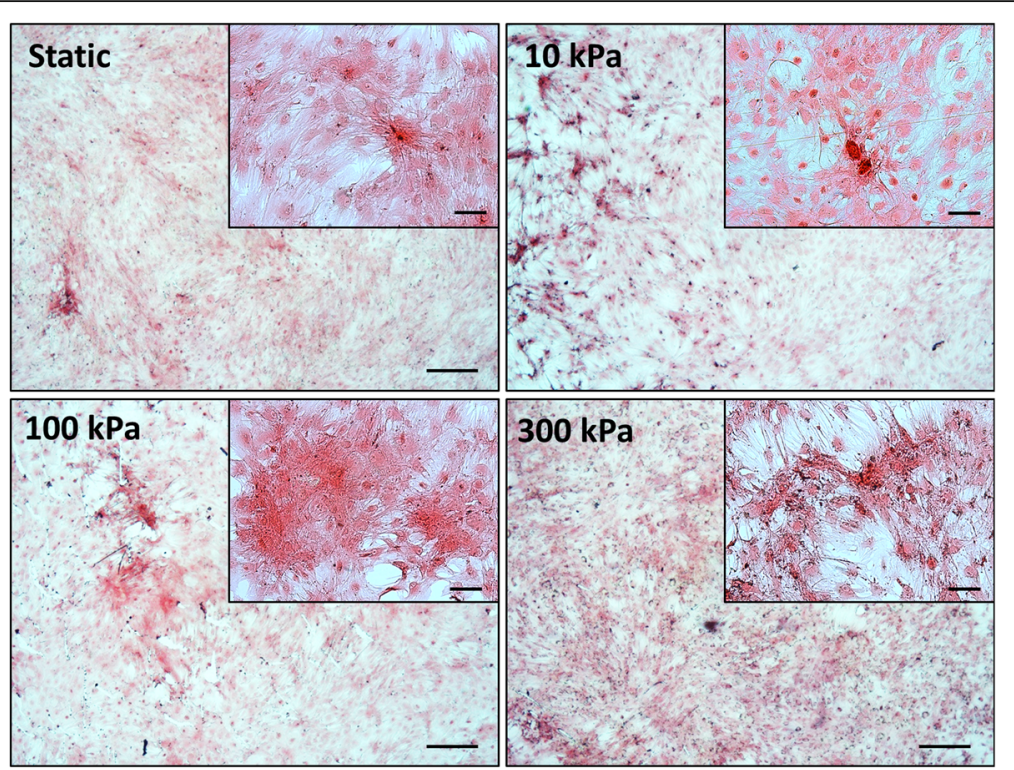

Fig. 6 PicroSirius Red staining for collagen after long term pressure stimulation (4 days loading and 17 days static). Static -static condition in minimum osteogenic conditions, pressure mechanical stimulation in minimum osteogenic conditions at $10 \mathrm{kPa}, 100 \mathrm{kPa}$ and $300 \mathrm{kPa}$ at $2 \mathrm{~Hz}$ frequency. Scale bar $=250 \mu \mathrm{m}$

should be considered when studying pressure driven fluid shear effects in hBMSC mechanobiology. Moreover, these findings may open new avenues for orthopaedic regenerative medicine strategies, in addition to providing novel platforms to characterise loading induced skeletal stem cell osteogenesis.

Human BMSCs were found to be mechanosensitive to pressure stimuli and elicited magnitude, frequency and duration dependent osteogenic responses to physiological bone CHP. COX2 and OPN mRNA expression were found to be magnitude dependent at $2 \mathrm{~Hz}, 2 \mathrm{~h}$ and $0.5 \mathrm{~Hz}, 4 \mathrm{~h}$ whereas RUNX2 expression did not demonstrate this dose-dependent effect, possibly highlighting activation of alternative pathways. Moreover, when normalising for the number of oscillations comparing $1 \mathrm{~Hz}$, $2 \mathrm{~h}$ versus $2 \mathrm{~Hz}, 1 \mathrm{~h}$ (120 oscillations), COX2 and OPN mRNA expression is similar and independent of pressure magnitude, whereas, when doubling the amount of oscillations at $2 \mathrm{~Hz}, 2 \mathrm{~h}$ and $0.5 \mathrm{~Hz}, 4 \mathrm{~h}$ (240 oscillations) the magnitude effects become significant. This may indicate that for magnitude dependent effects a cumulative threshold of stimulation must be reached for differential expression of osteogenic genes to be elicited. COX2 expression was shown to be sensitive to the magnitude of fluid flow stimulation in both osteocytes and stem cells and its expression has been highlighted as a precursor for osteoblastogenesis [11, 36, 37]. Pressure-induced COX2 expression was found to be elicited in osteocytes $(68 \mathrm{kPa}, 0.5 \mathrm{~Hz})$ and osteoblasts $(68 \mathrm{kPa}, 0.5 \mathrm{~Hz})$ but not hBMSCs $(50 \mathrm{kPa}, 2 \mathrm{~Hz})$, which may indicate that the pressure response was either frequency or lineage dependent $[24,30,38]$. Given that CHP induced a magnitude dependent response in our experimental setup, this could be attributed to the prior biochemical priming of hBMSC for 2 days before mechanical stimulation. However, we have also observed pressure induced Cox2 upregulation in a mesenchymal stem cell line (MSC), $\mathrm{C} 3 \mathrm{H} 10 \mathrm{~T} 1 / 2$ using the same system, highlighting the possibility in the difference of the bioreactor set up and mode of pressurisation in other studies (data not shown).

Interestingly, the overall expression of $O P N$ seemed unaltered or inhibited when compared to static culture, with several exceptions of positive magnitude effect at $0.5 \mathrm{~Hz}$ and $2 \mathrm{~Hz}$ frequencies. Changes in OPN mRNA levels have been reported to depend on the stage of osteogenic differentiation, as osteoprogenitor cells were found to exhibit lower basal levels and no changes in Opn mRNA expression in response to $13 \mathrm{kPa}, 0.3 \mathrm{~Hz}$ CHP when compared to late-stage osteoblasts [27]. Similarly, the observation that the master transcription factor RUNX2 remained unaltered or downregulated in some CHP regimes, may indicate that either CHP inhibits osteogenesis or alternatively results in changes in the translation of the protein, as has been previously shown in osteoblasts using a cyclic stretch model [39]. Interestingly, CHP was previously shown to stimulate collagen synthesis and bone mineral deposition in chick femurs, although no changes in Runx2 expression were observed [40]. Similar to our observations, pressure induced osteogenic lineage commitment of hBMSCs, in spite of unaltered $R U N X 2$ expression, alluding to the latter case of changes in protein translational activity. 


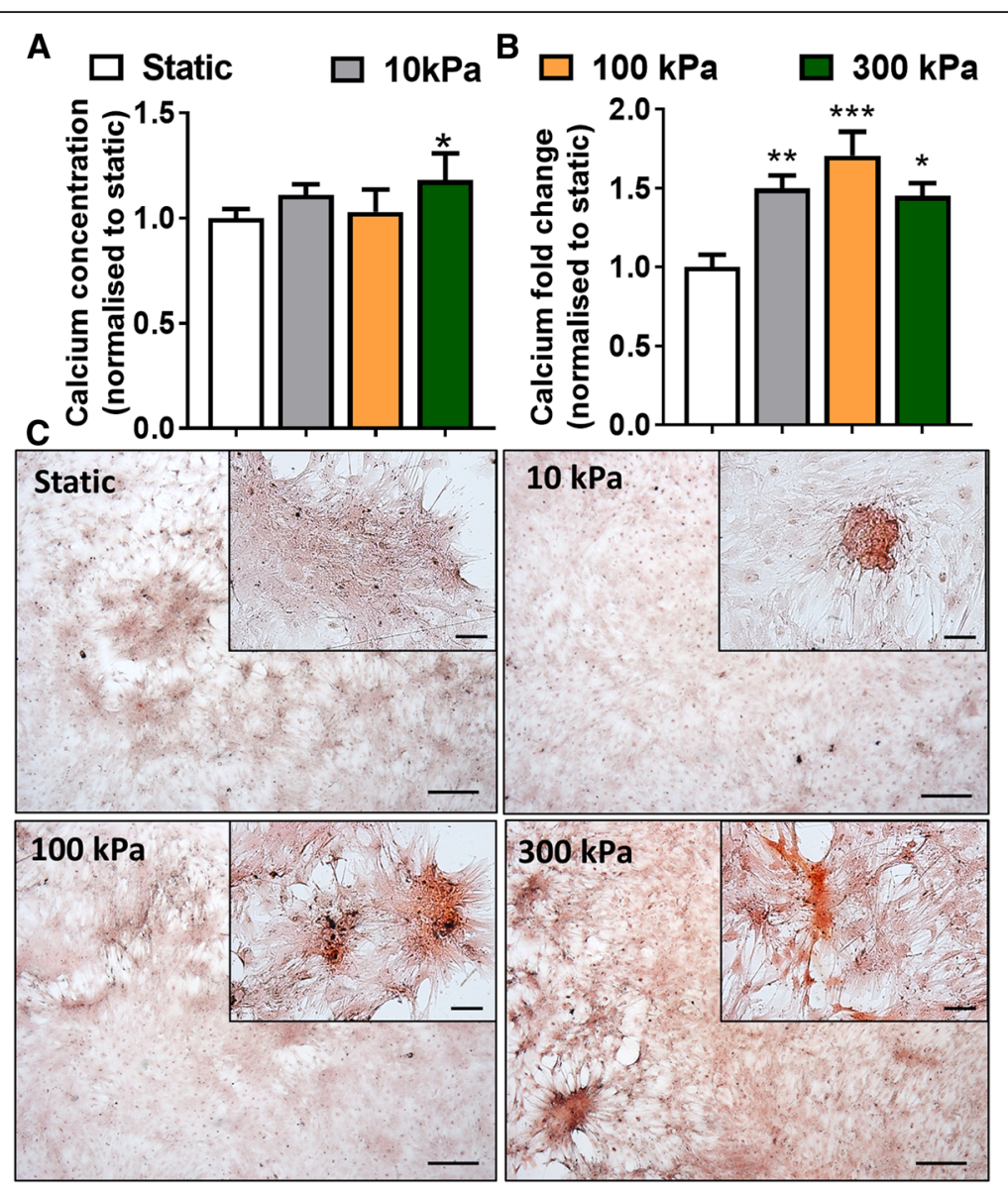

Fig. 7 Cyclic hydrostatic pressure stimulation induces mineralisation of hBMSCs. A) Calcium concentration after 4 days of CHP +10 days static culture (a) and 4 days of $\mathrm{CHP}+17$ days static culture (b). Alizarin $\mathrm{S}$ staining for mineralisation after long term pressure stimulation show presence of mineral nodules with CHP (4 days CHP + 17 days static culture) (c). Static-static condition in minimum osteogenic conditions, pressure mechanical stimulation in minimum osteogenic conditions at $10 \mathrm{kPa}, 100 \mathrm{kPa}$ and $300 \mathrm{kPa}$ at $2 \mathrm{~Hz}$ frequency. Scale bar $=250 \mu \mathrm{m} .{ }^{*} p<0.05,{ }^{* *} p<0.01,{ }^{* * *} p<0.001$

Pressure induced an early osteogenic response in hBMSC showing frequency dependent effects which were magnitude-gene coupled. Specifically, COX2 mRNA expression displayed a frequency dependent effect at $300 \mathrm{kPa}$ magnitude, whereas RUNX2 and OPN at $10 \mathrm{kPa}$ CHP. Interestingly, fluid flow induced Cox2 mRNA expression in both MSCs and osteocytes was found to have weak frequency effects, except at high magnitudes, demonstrating this mechanically driven COX2 response is consistent across all forms of mechanical stimulation. Increase in bone formation due to CHP stimulation in chick femurs was found to be proportional to frequency but independent of pressure magnitude applied [40]. Similarly, $2 \mathrm{~Hz}$ was found to be the optimum frequency for loading-induced mineralisation in an osteoblast model of dynamic compression [41]. This effect may be attributed to a universal magnitude-frequency response, possibly related to human kinematics and loading-induced bone formation $[11,36,42,43]$.
During long-term stimulation, using the most pro-osteogenic magnitude dependent $2 \mathrm{~Hz}$ frequency regime, we observed that hBMSC were mechanoresponsive to CHP loading overtime by secreting ATP metabolites into the medium. Moreover, this ATP release was magnitude depedent over time at each loading event. To date, only osteoblasts have been shown to elicit an ATP response to CHP, whereas, stem cells were found to secrete ATP in a fluid flow magnitude dependent manner [44-46]. Purinergic signalling plays a crucial role in bone anabolism, therefore ATP synthesis in response to mechanical stimulation may highlight initiation of mechanotransduction events, irrespective of type of stimulus [47-49]. Although hBMSCs display a pressure magnitude dependent sensitivity for ATP release, this did not correlate with the ability to synthesise bone mineral indicating that other mechanisms may be at play.

Cyclic hydrostatic pressure induces osteogenic lineage commitment of skeletal stem cells independent of magnitude of stimulation. This supports various reports, where 
pressure induced mineralisation in osteoblasts and stem cells, was shown to be modulated in vitro at low $(<40 \mathrm{kPa})$ and high $(200 \mathrm{kPa})$ magnitudes, either statically or dynamically [27-29, 31, 50, 51]. Ex vivo intramedullary pressurisation of ulnae, independent of matrix deformation, showed a positive correlation between transcortical pressure gradients and enhanced bone formation. This effect was associated to fluid flow, as transcortical pressure gradients are related to fluid flow velocity [10]. Similarly, magnitude of shear stress, at the same frequency $(2 \mathrm{~Hz})$ of CHP stimulation, was shown to elicit a positive effect on mineralisation in stem cells [11]. Biomechanically, bone deformation causes pressurisation of intraosseous fluid which forces it to flow within the bone. Given the incompressibility of the water based intraosseous fluid, small pressure gradients can elicit large inertial fluid effects due to the architecture of bone tissue. From this perspective, and the biological effects reported above, it can be concluded that pressure gradients play a role in hBMSCs osteogenesis, but this effect may be secondary to fluid flow. However, since fluid flow bioreactors rely on pressure driven flow that at often times reach pressure differentials higher than $10 \mathrm{kPa}$, these pressure effects should be accounted for in mechanobiology studies. A limitation of this study is that only the $2 \mathrm{~Hz}$ frequency CHP regime was used for long term pressure induced osteogenesis, hence these effects may be specific to this frequency alone.

\section{Conclusion}

In conclusion, we demonstrate that hBMSCs are mechanosensitive to pressure stimuli with a magnitude-dependent COX2 mRNA expression and ATP-associated purinergic signalling. Although RUNX2 and OPN mRNA expression remained unaltered with short-term CHP stimulation, application of physiologically associated cyclic hydrostatic pressures, over a long term, was found to induce osteogenic lineage commitment of hBMSCs, which was independent of pressure magnitude and frequency. This highlights that physiologically low marrow pressures can also affect the hBMSCs osteogenic potential, similar to fluid flow; however, its effects may be secondary. The systematic approach taken enabled the identification of early pressure differential effects which can be used to delineate the mechanisms of pressure induced osteogenesis. This can also serve as a platform to discover novel targets for bone therapies [31]. Moreover, these findings may support the use of mechanotherapies in clinical applications for patients displaying osteopenia/bone fragility, in addition to optimisation of bioreactor design for bone regenerative strategies.

\section{Additional file}

Additional file 1: Figure S1. Validation of trilineage potential of hBMSC for adipogenesis (Oil red $\mathrm{O}, \mathrm{A}$ ), chondrogenesis (Alician Blue, B) and osteogenesis (Alizarin Red S, C) after 21 days in culture. Zoomed in images point to triglyceride accumulation in adipogenic conditions. Scale bar $=200 \mu \mathrm{m}$. Figure S2 Schematic of long term pressure mechanical stimulation regime. (DOCX $600 \mathrm{~kb}$ )

\begin{abstract}
Abbreviations
18s: 18s ribosomal RNA; ALP: Alkaline phosphotase; ATP: Adenosine triphosphate; BMP2: Bone morphogenetic protein 2; BMSC: Bone marrowderived stem cells; cDNA: Circular deoxyribonucleic acid; CHP: Cyclic hydrostatic pressure; Cox2: Cyclooxygenase 2; Dlx5: Distal-less homeobox 5; DMEM: Dulbecco's modified Eagle medium; FBS: Fetal bovine serum; GAPDH: Glyceraldehyde 3-phosphate dehydrogenase; hBMSC: Human bone marrow-derived stem cells; HP: Hydrostatic pressure; IMP: Intramedullary pressure; LABVIEW: Laboratory Virtual Instrument Engineering Workbench; LCS: Lacunar canalicular system; mRNA: Messenger ribonucleic acid; MSC: Mesenchymal stem cells; Msx2: Msh homeobox 2; nM: Nanomolar; Opn: Osteopontin; Osx: Osterix; P/S: Penicillin streptomycin; qPCR: Quantitative polymerase chain reaction; RNA/rna: Ribonucleic acid; Runx2: Runt-related transcription factor 2
\end{abstract}

\section{Acknowledgements}

We would like to acknowledge the workshop of the Mechanical, Aeronautical and Biomedical Engineering Department within the University of Limerick for the manufacture of the pressure bioreactors.

\section{Funding}

The study was supported by a European Research Council (ERC) Starting Grant (\#336882) and a Science Foundation Ireland ERC Support Grant SFI 13/ ERC/L2864 (to D.A.H.).

\section{Availability of data and materials}

The datasets analysed during the current study are available from the corresponding author on reasonable request.

\section{Authors' contributions}

ES carried out the experimental lab work, participated in data analysis, participated in the design of the study and drafted the manuscript. GPJ, MC and MR carried out experimental work. ES and DH participated in data analysis, participated in the design of the study and drafted the manuscript. All authors gave the final approval for publication.

\section{Ethics approval and consent to participate}

Not applicable. Human bone marrow-derived skeletal stem cells (hBMSCs) were isolated from bone marrow aspirates purchased from Lonza.

\section{Consent for publication}

All authors have contributed to, read and approved the final manuscript for submission.

\section{Competing interests}

The authors declare that they have no competing interests.

\section{Publisher's Note}

Springer Nature remains neutral with regard to jurisdictional claims in published maps and institutional affiliations.

\section{Author details}

${ }^{1}$ Trinity Centre for Bioengineering, Trinity Biomedical Sciences Institute, Trinity College Dublin, Dublin 2, Ireland. ²Department of Mechanical and Manufacturing Engineering, School of Engineering, Trinity College Dublin, Dublin 2, Ireland. ${ }^{3}$ Department of Mechanical, Aeronautical and Biomedical Engineering, University of Limerick, Limerick, Ireland. ${ }^{4}$ Advanced Materials and Bioengineering Research Centre, Trinity College Dublin and RCSI, Dublin 2, Ireland. 
Received: 1 May 2018 Revised: 27 August 2018

Accepted: 30 September 2018 Published online: 25 October 2018

\section{References}

1. Robling $\mathrm{AG}$, Castillo $\mathrm{AB}$, Turner $\mathrm{CH}$. Biomechanical and molecular regulation of bone remodeling. Annu Rev Biomed Eng. 2006;8:455-98.

2. Hu M, Cheng J, Qin YX. Dynamic hydraulic flow stimulation on mitigation of trabecular bone loss in a rat functional disuse model. Bone. 2012;51(4):819-25.

3. Kwon RY, Meays DR, Tang WJ, Frangos JA. Microfluidic enhancement of intramedullary pressure increases interstitial fluid flow and inhibits bone loss in hindlimb suspended mice. J Bone Miner Res. 2010;25(8):1798-807.

4. Lee KL, Hoey DA, Spasic M, Tang T, Hammond HK, Jacobs CR. Adenylyl cyclase 6 mediates loading-induced bone adaptation in vivo. FASEB J. 2014; 28(3):1157-65.

5. Ren L, Yang P, Wang Z, Zhang J, Ding C, Shang P. Biomechanical and biophysical environment of bone from the macroscopic to the pericellular and molecular level. J Mech Behav Biomed Mater. 2015;50:104-22.

6. Chen JC, Hoey DA, Chua M, Bellon R, Jacobs CR. Mechanical signals promote osteogenic fate through a primary cilia-mediated mechanism. FASEB J. 2016;30(4):1504-11.

7. Curtis KJ, Coughlin TR, Mason DE, Boerckel JD, Niebur GL. Bone marrow mechanotransduction in porcine explants alters kinase activation and enhances trabecular bone formation in the absence of osteocyte signaling. Bone. 2018;107:78-87.

8. Kwon RY, Meays DR, Meilan AS, Jones J, Miramontes R, Kardos N, Yeh JC, Frangos JA. Skeletal adaptation to intramedullary pressure-induced interstitial fluid flow is enhanced in mice subjected to targeted osteocyte ablation. PLoS One. 2012;7(3):e33336.

9. Hillsley M, Frangos J. Bone tissue engineering: the role of interstitial fluid flow. Biotechnol Bioeng. 1994;43(7):573-81.

10. Qin Y-X, Kaplan T, Saldanha A, Rubin C. Fluid pressure gradients, arising from oscillations in intramedullary pressure, is correlated with the formation of bone and inhibition of intracortical porosity. J Biomech. 2003;36(10):1427-37.

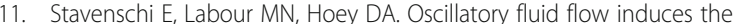
osteogenic lineage commitment of mesenchymal stem cells: the effect of shear stress magnitude, frequency, and duration. J Biomech. 2017:55:99-106.

12. Govey PM, Loiselle AE, Donahue HJ. Biophysical regulation of stem cell differentiation. Curr Osteoporos Rep. 2013;11(2):83-91.

13. Eichholz KF, Hoey DA. Mediating human stem cell behaviour via defined fibrous architectures by melt electrospinning writing. Acta Biomater. 2018;75:140-51.

14. Metzger TA, Kreipke TC, Vaughan TJ, McNamara LM, Niebur GL: The in situ mechanics of trabecular bone marrow: the potential for mechanobiological response. J Biomech Eng 2015, 137(1):011006-011006-7.

15. Ochoa JA, Sanders AP, Heck DA, Hillberry BM. Stiffening of the femoral head due to intertrabecular fluid and intraosseous pressure. J Biomech Eng. 1991; 113(3):259-62

16. Brady RT, O'Brien FJ, Hoey DA. Mechanically stimulated bone cells secrete paracrine factors that regulate osteoprogenitor recruitment, proliferation, and differentiation. Biochem Biophys Res Commun. 2015:459(1):118-23.

17. Hoey DA, Kelly DJ, Jacobs CR. A role for the primary cilium in paracrine signaling between mechanically stimulated osteocytes and mesenchymal stem cells. Biochem Biophys Res Commun. 2011;412(1):182-7.

18. Hoey DA, Tormey S, Ramcharan S, O'Brien FJ, Jacobs CR. Primary ciliamediated mechanotransduction in human mesenchymal stem cells. Stem Cells. 2012;30(11):2561-70.

19. Downey DJ, Simkin PA, Taggart R. The effect of compressive loading on intraosseous pressure in the femoral head in vitro. J Bone Joint Surg Am. 1988;70(6):871-7.

20. Bryant JD. The effect of impact on the marrow pressure of long bones in vitro. J Biomech. 1983;16(8):659-65.

21. Kumar S, Davis PR, Pickles B. Bone-marrow pressure and bone strength. Acta Orthop Scand. 1979;50(5):507-12

22. Riddle RC, Donahue HJ. From streaming-potentials to shear stress: 25 years of bone cell mechanotransduction. J Orthop Res. 2009;27(2):143-9.

23. Chung BJ, Robertson AM, Peters DG. The numerical design of a parallel plate flow chamber for investigation of endothelial cell response to shear stress. Comput Struct. 2003:81(8-11):535-46.

24. Gardinier JD, Majumdar S, Duncan RL, Wang L. Cyclic hydraulic pressure and fluid flow differentially modulate cytoskeleton re-organization in MC3T3 osteoblasts. Cell Mol Bioeng. 2009;2(1):133-43.
25. Jacobs CR, Yellowley CE, Davis BR, Zhou Z, Cimbala JM, Donahue HJ. Differential effect of steady versus oscillating flow on bone cells. J Biomech 1998:31:969-78

26. Burger EH, Klein-Nulend J, Veldhuijzen JP. Mechanical stress and osteogenesis in vitro. J Bone Miner Res. 1992;7(Suppl 2):S397-401.

27. Klein-Nulend J, Roelofsen J, Semeins CM, Bronckers ALJJ, Burger EH. Mechanical stimulation of osteopontin mRNA expression and synthesis in bone cell cultures. J Cell Physiol. 1997;170:174-81.

28. Nagatomi J, Arulanandam BP, Metzger DW, Meunier A, Bizios R. Cyclic pressure affects osteoblast functions pertinent to osteogenesis. Ann Biomed Eng. 2003;31(8):917-23.

29. Roelofsen J, Klein-Nulend J, Burger E. Mechanical stimulation by intermittent hydrostatic compression promotes bone-specific gene expr. J Biomech. 1995;28(12):1493-503.

30. Becquart $\mathrm{P}$, Cruel $\mathrm{M}$, Hoc $\mathrm{T}$, Sudre L, Pernelle $\mathrm{K}$, Bizios $\mathrm{R}$, LogeartAvramoglou D, Petite $H$, Bensidhoum M. Human mesenchymal stem cell responses to hydrostatic pressure and shear stress. Eur Cell Mater. 2016;31:160-73

31. Sugimoto A, Miyazaki A, Kawarabayashi K, Shono M, Akazawa Y, Hasegawa T, Ueda-Yamaguchi K, Kitamura T, Yoshizaki K, Fukumoto S, et al. Piezo type mechanosensitive ion channel component 1 functions as a regulator of the cell fate determination of mesenchymal stem cells. Sci Rep. 2017;7(1):17696.

32. Liu J, Zhao Z, Li J, Zou L, Shuler C, Zou Y, Huang X, Li M, Wang J. Hydrostatic pressures promote initial osteodifferentiation with ERK1/2 not p38 MAPK signaling involved. J Cell Biochem. 2009;107:224-32.

33. Zhao YH, Lv X, Liu YL, Zhao Y, Li Q, Chen YJ, Zhang M. Hydrostatic pressure promotes the proliferation and osteogenic/chondrogenic differentiation of mesenchymal stem cells: the roles of RhoA and Rac1. Stem Cell Res. 2015; 14:283-96.

34. Danion F, Varraine $\mathrm{E}$, Bonnard $\mathrm{M}$, Pailhous J. Stride variability in human gait: the effect of stride frequency and stride length. Gait Posture. 2003; 18(1):69-77.

35. Nagaraja MP, Jo H. The role of mechanical stimulation in recovery of bone loss-high versus low magnitude and frequency of force. Life. 2014;4(2):117-30

36. Li J, Rose E, Frances D, Sun Y, You L. Effect of oscillating fluid flow stimulation on osteocyte mRNA expression. J Biomech. 2012;45(2):247-51.

37. Zhang X, Schwarz EM, Young DA, Puzas JE, Rosier RN, O'Keefe RJ. Cyclooxygenase-2 regulates mesenchymal cell differentiation into the osteoblast lineage and is critically involved in bone repair. J Clin Investig. 2002;109(11):1405-15

38. Liu C, Zhao Y, Cheung WY, Gandhi R, Wang L, You L. Effects of cyclic hydraulic pressure on osteocytes. Bone. 2010;29:997-1003.

39. Zuo B, Zhu J, Li J, Wang C, Zhao X, Cai G, Li Z, Peng J, Wang P, Shen $C$, et al. microRNA-103a functions as a mechanosensitive microRNA to inhibit bone formation through targeting Runx2. J Bone Miner Res. 2015:30(2):330-45

40. Henstock JR, Rotherham M, Rose JB, El Haj AJ. Cyclic hydrostatic pressure stimulates enhanced bone development in the foetal chick femur in vitro. Bone. 2013;53(2):468-77

41. Tanaka SM, Tachibana K. Frequency-dependence of mechanically stimulated osteoblastic calcification in tissue-engineered bone in vitro. Ann Biomed Eng. 2015:43(9):2083-9.

42. Zhao L, Dodge T, Nemani A, Yokota H. Resonance in the mouse tibia as a predictor of frequencies and locations of loading-induced bone formation. Biomech Model Mechanobiol. 2014;13(1):141-51.

43. Hsieh $Y$, Turner $C$. Effects of loading frequency on mechanically induced bone formation. J Bone Miner Res. 2001;16(5):918-24.

44. Gardinier JD, Gangadharan V, Wang L, Duncan RL. Hydraulic pressure during fluid flow regulates purinergic signaling and cytoskeleton organization of osteoblasts. Cell Mol Bioeng. 2014;7(2):266-77.

45. Riddle RC, Hippe KR, Donahue HJ. Chemotransport contributes to the effect of oscillatory fluid flow on human bone marrow stromal cell proliferation. J Orthop Res. 2008:26(7):918-24.

46. Riddle RC, Taylor AF, Rogers JR, Donahue HJ. ATP release mediates fluid flow-induced proliferation of human bone marrow stromal cells. J Bone Miner Res. 2007;22(4):589-600.

47. Ciciarello M, Zini R, Rossi L, Salvestrini V, Ferrari D, Manfredini R, Lemoli RM. Extracellular purines promote the differentiation of human bone marrowderived mesenchymal stem cells to the osteogenic and adipogenic lineages. Stem Cells Dev. 2013;22(7):1097-111. 
48. Noronha-Matos JB, Correia-de-Sa P. Mesenchymal stem cells ageing: targeting the "Purinome" to promote osteogenic differentiation and bone repair. J Cell Physiol. 2016;231(9):1852-61.

49. Li W, Li G, Zhang Y, Wei S, Song M, Wang W, Yuan X, Wu H, Yang Y. Role of P2 $\times 7$ receptor in the differentiation of bone marrow stromal cells into osteoblasts and adipocytes. Exp Cell Res. 2015;339(2):367-79.

50. Burger EH, Klein-Nulend J, Veldhuijzen JP. Modulation of osteogenesis in fetal bone rudiments by mechanical stress in vitro. J Biomech. 1991; 24(Suppl 1):101-9.

51. Kim SH, Park SH, Jun JW, Kim DH, Shin JW, Han JY, Kang YG, Shin JW. Hydrostatic pressure can control osteogenesis and osteoclastogenesis when stromal cells and osteoclast precursor cells are cocultured. Tissue Eng Regen Med. 2010;7(4):388-94.

Ready to submit your research? Choose BMC and benefit from:

- fast, convenient online submission

- thorough peer review by experienced researchers in your field

- rapid publication on acceptance

- support for research data, including large and complex data types

- gold Open Access which fosters wider collaboration and increased citations

- maximum visibility for your research: over $100 \mathrm{M}$ website views per year

At BMC, research is always in progress.

Learn more biomedcentral.com/submissions 